Fifth International Conference on Sustainable Construction Materials and

Technologies. http://www.claisse.info/Proceedings.htm

\title{
APPLICABLE USE OF LIGHTWEIGHT FOAM CONCRETE COMPOSITE SANDWICH PANELS AS A FLOORING SYSTEM
}

${ }^{[1]}$ Hisham Alabduljabbar, ${ }^{[2]}$ Rayed Alyousef, ${ }^{[3]}$ Y. H. Mugahed Amran

${ }^{[1]}$ Department of Civil Engineering, College of Engineering, Prince Sattam Bin Abdulaziz University, 11942

Alkharj, KS, ${ }^{[2]}$ Department of Civil Engineering, College of Engineering, Prince Sattam Bin Abdulaziz University, 11942 Alkharj, KSA, ${ }^{[3]}$ Department of Civil Engineering, Faculty of Engineering, Amran University (AU), 1 Quhal, Amran Province, Yemen,

${ }^{[1]} \underline{h . a l a b d u l j a b b a r @ p s a u . e d u . s a},{ }^{[2]} \underline{\text { r.alyousef@psau.edu.sa, }},{ }^{[3]}$ mugahed_amran@hotmail.com

\begin{abstract}
Experimental and analytical studies were conducted to investigate the structural performance of lightweight foam concrete composite sandwich panels (LFCCSP) of total number six as one-way action slab, differing in their thickness and tested under out-of-plane load. The details of the test setup and procedures were demonstrated. The results attained from the experimental tests were analysed and discussed which comprise, compressive and flexural strengths of foam concrete, the influence of aspect ratio (L/b), and observation of cracking patterns. Also, the analytical study of finite element analysis (FEA) using LUSAS software was employed and the degree of composite action of the test LFCCSP panels was also studied in both analytical and experimental studies. Result displays that crack patterns appeared in only one-direction with similar behaviour reported on solid slabs, in particular, at the case when both concrete wythes act as one structural composite unit. Foam concrete (FC) was briefly used to cast LFCCSP panels. The experimental results were compared with the given FEA data, showing a reasonable degree of accuracy. Hence, in the basis of the results obtained, LFCCSP slab can be used as a substitute system element to traditional flooring system.
\end{abstract}

Keywords: Lightweight Foam Concrete Composite Sandwich Panels (LFCCSP), Foam Concrete (FC), Finite Element Analyses (FEA), Aspect ratio (L/b), ultimate lateral strength capacity.

\section{INTRODUCTION}

The precast concrete sandwich slab panel (PCSSP) is the second component of building envelope structures after wall bearing system. PCSSPs are fundamentally designed to be installed in the horizontal direction in the constructing of either floor or roof system components. Structural slabs come in numerous types, including solid, composite, hollow core, double $\mathrm{T}$, flat, beam and block floor, and ferrocement-AAC composite slabs (Fig. 1). The composite slab is usually developed into two types, namely, steel decking and precast concrete. Meanwhile, precast concrete systems comprise two layers, namely, the precast and in situ layers $[1,2]$. However, the steel decking systems is commonly sustained by steel joists or beams. It is utilised to structurally-support concrete of a roof and flooring systems. It usually comes with several design configurations which can provide the ultimate steel decking solution for high-rise buildings. It can afford excellent acoustic recital, protection to fire, provides a high strength-to-weight ratio, and incorporate to thermal mass.

The performance of PCSSPs depends on several factors, such as typical design shape, number, spacing, arrangement of mechanical shear connectors, and spacing of steel reinforcement bars [3,4]. These factors generally influence the global shear strength contributed by PCSSPs. Moreover, mechanical shear connectors exert have a major influence on the structural integrity or thermal insulation performance of PCSSPs. Shear connectors should have enough strength capacity to transfer shear loads and bending 
moment from the top to the bottom concrete wythes and control the deflection associated with the overall depth of the wythes. Furthermore, a slab structure element formalizes the largest proportion of the total dead load and the volume of traditional residential buildings. The self-weight of a slab contributes to $40 \%-60 \%$ of the total dead load of a residential building structure [5]. Therefore, a reduction of nearly $10 \%$ in the self-weight of a floor slab may lead to a $5 \%$ reduction in the self-weight of an entire building. Many researchers have conducted extensive studies on PCSSPs, but only a few have regarded the use of lightweight materials to reduce the self-weight of building superstructures [3, 5, 6-9].

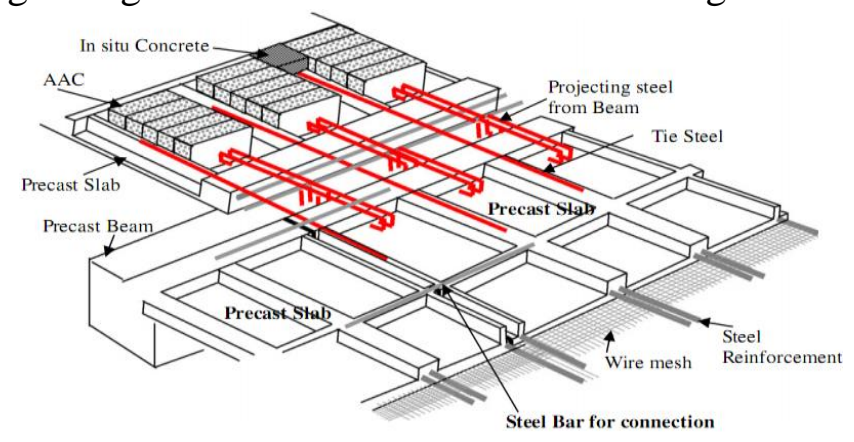

Fig. 1: Typical design of a ferrocement-AAC composite slab [5]

\section{FOAMED CONCRETE (FC)}

FC is defined as light cellular concrete, which is classified as lightweight concrete (density of 400-1850 $\mathrm{kg} / \mathrm{m}^{3}$ ) with random air voids created from the mixture of foaming agents in mortar [10]. FC is recognized for its high flowability, low cement content and aggregate usage and excellent thermal insulation [10-12]. FC is also considered as an economical solution to the fabrication of large-scale lightweight construction materials and components, such as structural components, partitioning, filling grades, and road embankment infill [11-14]. In this study, FC was used in the production of LFCCSP to be used as a flooring system where the FC has shown its superior practical use in casting sandwich panels for both wall and slab systems [12-14].

\section{DESIGN AND FABRICATION OF LFCSP AND MATERIAL PROPERTIES}

A total of six LFCCSP specimens (S1-S6) varying in spans were cast in timber formwork using foamed concrete plus one control specimen (SC) cast using normal concrete and then tested. The proportions of FC mix design were cement, sand and water, with values of 541:1080:243, per $\mathrm{m}^{3}$, respectively. Also, a protein foam agent of $82 \mathrm{~kg} / \mathrm{m}^{3}$ volume was added to the FC mix. A square welded mild mesh of $6 \mathrm{~mm}$ diameter deformed bars with $100 \mathrm{~mm} \times 100 \mathrm{~mm}$ openings were used as longitudinal and transverse reinforcements for both inner and outer concrete wythes of LFCCSP. Five steel truss-shaped shear connectors made of $6 \mathrm{~mm}$ diameter round mild steel bars with $45^{\circ}$ inclination angle ran along the heights of LFCCSP. The insulation layer was made from expanded polystyrene (EPS) to stabilize both concrete wythes apart and enhances the thermal insulation performance.

The FC compressive strength, Fc, of 28 days was $24.83 \mathrm{MPa}$, elastic modulus, Ec, $17.74 \mathrm{kN} / \mathrm{mm}^{2}$ and splitting strength, fct, $1.89 \mathrm{~N} / \mathrm{mm} 2$. The shear connector and steel bar were having yield strength, fy 300 $\mathrm{MPa}$ and $490 \mathrm{MPa}$, elastic modulus, Es, $152 \mathrm{kN} / \mathrm{mm}^{2}$ and $112 \mathrm{kN} / \mathrm{mm}^{2}$, respectively. Furthermore, two types of electrical strain gauges (ESGs, with $120.2 \pm 0.2 \mathrm{~mm}$ accuracy values), namely, 67 and $2 \mathrm{~mm}$ lengths, were used to measure strains on surface of FC and steel, respectively.

\section{EXPERIMENTAL TEST SETUP AND PROCEDURES}

The developed LFCCSP specimens were varied in spans between $1750 \mathrm{~mm}$ to $4000 \mathrm{~mm}$ with $250 \mathrm{~mm}$ constant increment between former and subsequent specimen. The overall thickness of LFCSP is $170 \mathrm{~mm}$ as such divided into; $65 \mathrm{~mm}$ thickness of top and bottom concrete wythes each and $40 \mathrm{~mm}$ thickness of 
insulated layer in between with a $20 \mathrm{~mm}$ concrete cover.

All LFCCSP slab specimens were tested using a universal testing machine with $2000 \mathrm{kN}$ capacity under out-of-plane loads. The frame was fixed to a strong floor using anchor bolts. All LFCCSP specimens were horizontally seated, tested, and designed as a one-way slab action. The specimens were simply supported at the shorter sides. The out-of-plane loads were applied as two-line lateral loads (Fig. 2). The hydraulic jack was applied on a load cell activated by a manually operated pump. The applied load was transferred from the jack as a one-point load. This load was then distributed into a two-line load across the specimen width using a spender beam (I-beams) (Fig. 2). All the specimens were subjected to out-of-plane load until the ultimate load at failure. All the specimens were painted white for easy observation of the flexural crack patterns during testing. The specimens were properly positioned in the testing frame. Figures 3.8 and 3.9 illustrate the boundary conditions and end supports. The LVDTs were placed in three proper locations ( $1 / 4 L, 1 / 2 L$, and 3/4L along the specimen span and in line with the ASTM C78 standard (Fig. 2). The concrete strain gauges were glued at appropriate and critical positions to measure the concrete wythe strains. The instrumentation preparations were checked and properly adjusted prior to load application. A load of $1 \mathrm{kN}$ was first applied to ensure that all instruments were working properly. The load was made constant and was increased gradually at increments of approximately $2.5 \mathrm{kN}$ until the ultimate load of the tested specimen was reached. The strains in the steel reinforcement, shear connectors, and concrete at every stage were automatically measured and recorded using the data logger UCAM-70A|KYOWA equipped with a scanner USB-70A-10. Cracking patterns were observed and marked on the specimen surface at each load stage to indicate the corresponding load. The full-scale experimental investigation focused on the structural behavior of the specimens during the application of the out-of-plane load. Therefore, failure load was observed when extreme cracking occurred at the bottom wythes. The applied load began to drop as the deflection increased.

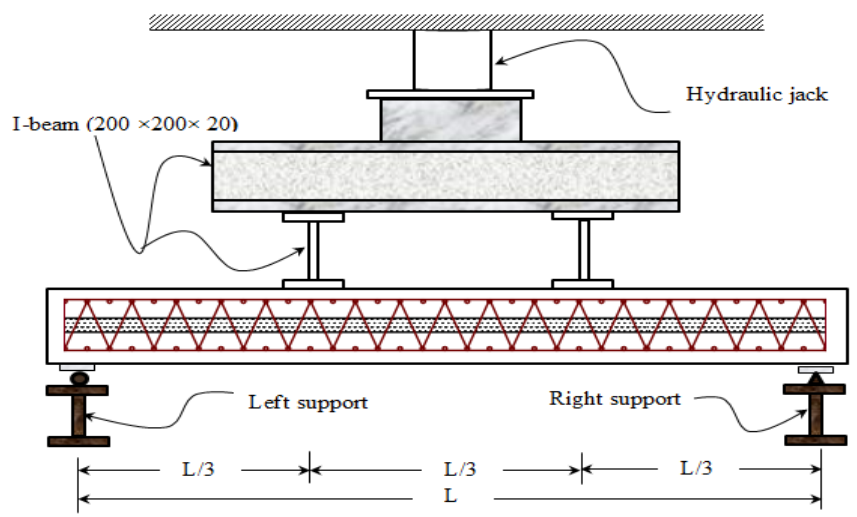

Fig. 2: Typical out-of-plane test frame and setup of the one-way slab

\section{ANALYSIS AND DISCUSSION OF THE RESULTS}

\section{A. Load-Deflection Profile}

Fig. 3 presents the set of loads versus mid-span deflection curves of all the slab specimens (S1-S6 and SC). The deflection also increased linearly up to a certain load, that is, yield load, as the load increased. The mid-span deflection varied non-linearly and reached the maximum value after that point. The deflection started to increase appreciably as the load decreased beyond the ultimate load point. The panels behaved in a linear elastic manner at the early testing stage until the load of the first crack $P=22.5 \mathrm{kN}$ was applied and a mid-span lateral deflection of $\Delta_{\mathrm{S} 1}=5.2 \mathrm{~mm}$ was observed for panel S1. The development of each flexural crack in the load-deflection plot was related to a visible drop in the load-deflection curve. The formation of the second flexural crack at a load of $P=26.7 \mathrm{kN}$ and a lateral deflection of $\Delta_{\mathrm{S} 1}=9.5$ $\mathrm{mm}$ was also noted. The first flexural cracks occurred at $41 \%$ to $52 \%$ of the failure load. The deflection values were about $11 \%$ to $15 \%$ of the ultimate load at mid-span of the tested slab panels. The deflection curve continuously increased for a given load increase beyond the load of the second flexural crack. The 
panels were loaded until the ultimate failure load was applied. Thus, it found that the deflection curves were decreased by about $12.37 \%$. Furthermore, the reduction in the deflection curves for panels S1 to S6 was deemed valuable for use because it was safe and achieved a high composite action. In the comparison of the load versus deflection curves, the ultimate load-carrying capacity and deflection modes of the LFCCSPs as one-way acting slabs comparatively agreed with those reported for PCSPs as one-way working slabs tested by researchers named Ellinna [15] and Benayoune, [16].

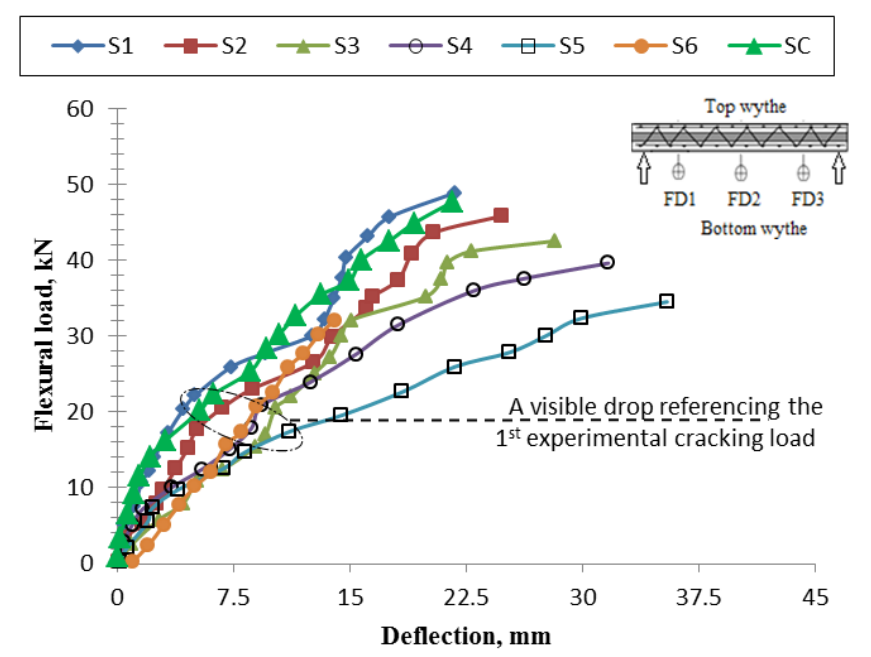

Fig. 3: Load-deflection profile at FD2 of mid-span for panels S1 to S6

Fig 4 shows the deflection profile along the span for slab panels S1 to S5 at different load levels. The increase in the deflection profile at mid-span of the tested slab was high only befor.e the ultimate load failure and was less significant at a low aspect ratio for the LFCCSP slabs. For instance, the deflection for panel S6 at $30.1 \mathrm{kN}$ load was $\Delta_{\mathrm{S} 6}=30.82 \mathrm{~mm}$. The deflection suddenly increased up to $\Delta_{\mathrm{s} 6}=39.84 \mathrm{~mm}$ at failure load $\mathrm{P}_{\mathrm{S} 6}=32.11 \mathrm{kN}$. Therefore, the deflection increased by almost $24.1 \%$ with a $2.10 \mathrm{kN}$ increase in the applied load. The maximum deflections at failure load for panels S1 and S6 were $\Delta_{\mathrm{S} 1}=21.75 \mathrm{~mm}$ and $\Delta_{\mathrm{S} 6}=39.84 \mathrm{~mm}$, respectively. The difference in the deflection values was nearly $83.2 \%$. However, the regular uniform distribution of the deflection profiles clearly indicated that the two concrete wythes behaved similarly to the solid slab at different loading levels; otherwise, irregular behavior would have been observed. The differences in the deflection and ultimate strength values of S1 and SC were approximately limited to $2.2 \%$ and $1.9 \%$, respectively

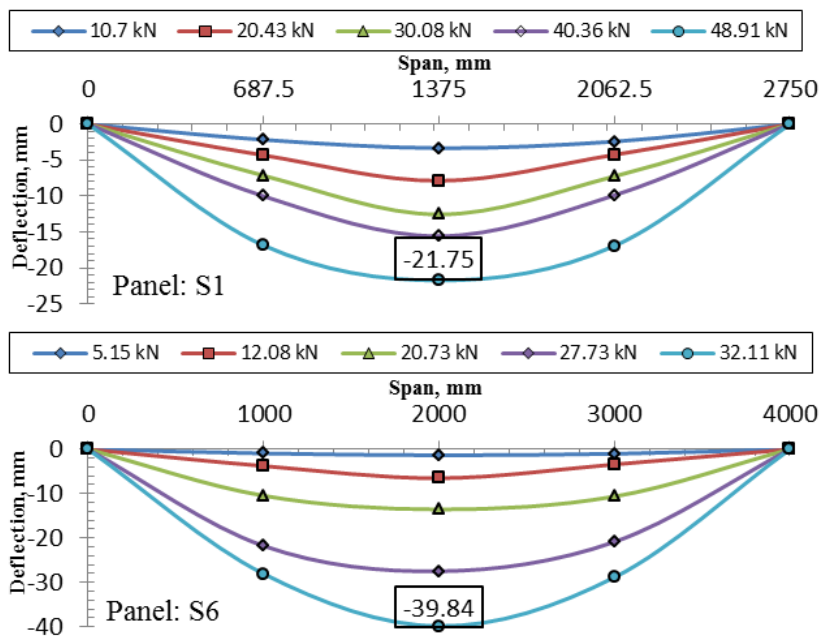

Fig. 4: Deflection along the span of panels S1 and S6 at different load stages 


\section{B. Load-Strain Relationship}

The recorded strains plotted in Fig. 5 were analyzed to study the structural efficacy of the shear connectors at mid-span of the LFCCSP slabs. The maximum strain that developed on the truss-shaped shear connector legs did not even exceed $985 \mu \varepsilon$ in SC1 of panel S1, whereas the remaining strains recorded as far as less the said value. The truss connector deformation began at $82.5 \%$ of the ultimate load. The load transfer from the upper wythe to the lower wythe was clearly efficient until the ultimate failure because a high composite action could be achieved even at the time of load termination.

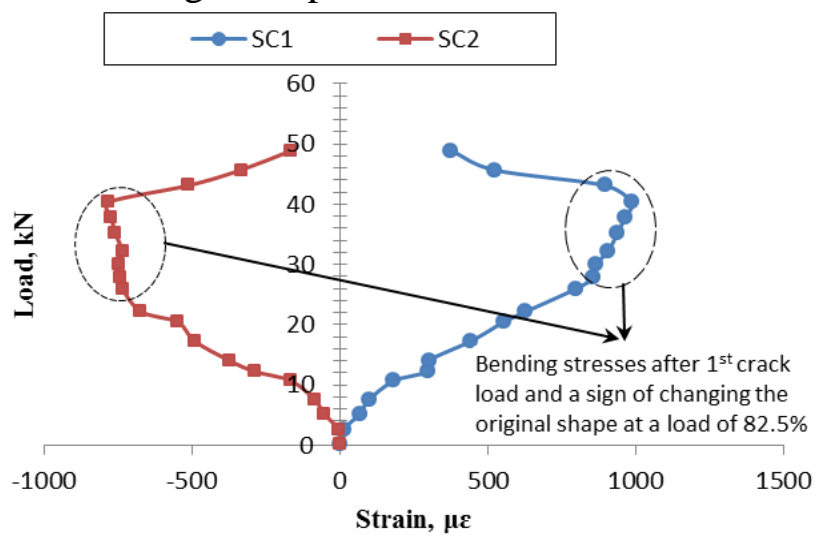

Fig. 5: Load-strain in the shear connector adjacent legs at mid-span for S1

\section{Strain Distribution}

Fig. 6 shows the typical strain variation across the depth at mid-height for the four LFCCSP slabs (S1, and S6) at different load levels. All panels exhibited a small discontinuity at the initial loading stage. This discontinuity became at the period before the application of the failure load. Furthermore, all panels were likely to show fully composite behavior when they were integrated by truss connectors with a $6 \mathrm{~mm}$ diameter, which assisted the panels in acting as a solid.

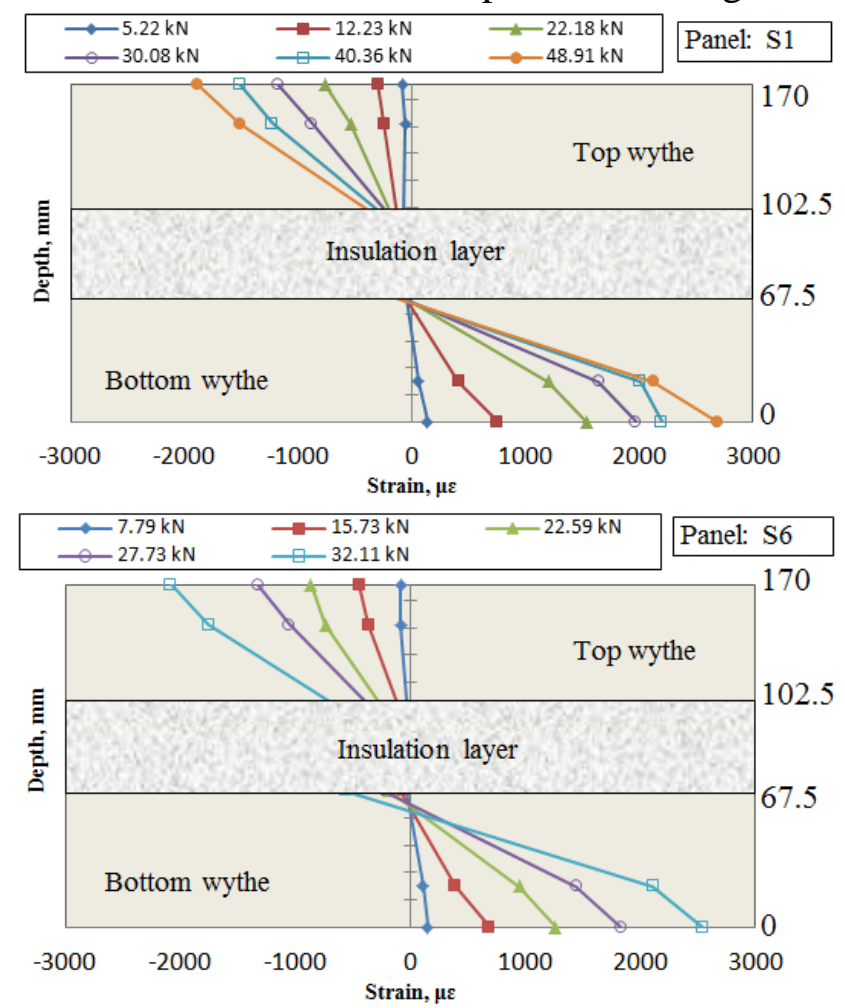

Fig. 6: Strain distribution across the $170 \mathrm{~mm}$ depth at different load stages for the tested panels

\section{Influence of Aspect Ratio}

Fig. 7 shows the influence of the aspect ratio of panels S1 to S6 under out-of-plane loads. The ultimate strength capacities of $\mathrm{S} 1$ of $\mathrm{L} / \mathrm{d}=16.18$ and $\mathrm{S} 6$ of $\mathrm{L} / \mathrm{d}=23.53$ allowed them to resist loads of 48.91 and $32.11 \mathrm{kN}$, respectively. The difference was that $\mathrm{S} 1$ could carry a $52.3 \%$ greater load than panel S6 with a 
7.35 difference in aspect ratio. The maximum drop of the ultimate strength was observed when the aspect ratio increased from 20.59 in S4 to 22.06 in S5 under about 14.8\% of the ultimate load. Fig. 8 shows the effect of aspect ratio versus the deflection profile for panels S1 to S6. The difference in the deflection values between S1 and S6 was almost 83.2\% when the difference in the aspect ratio was equal to 7.35.

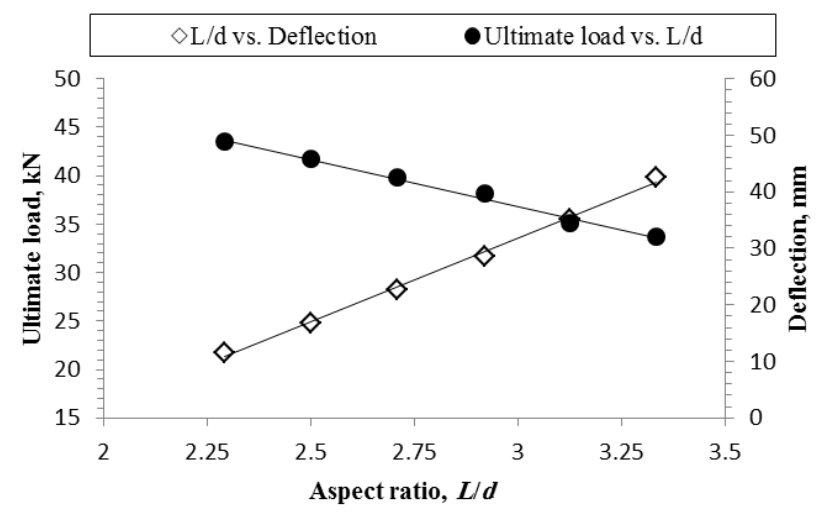

Fig. 7: Influence of aspect ratio (L/d) for panels S1 to S6

\section{FEA VALIDATION}

The simulated FEA model results were compared with those of the experimental tests to validate them and to determine the correlation level. The sizes of the panels used for the FEA validation were similar to the actual test specimens. Section IV presents relevant details on the test specimens and test setup.

\section{A. Load-Deflection Profile}

Fig. 8 shows the load-deflection profiles for panels S1 to S6 at different load increments at the mid-span of the 2D FEA model and specimen. The same figure also shows the theoretical extremes of the fully composite and non-composite panels using classical elastic theory. These ten panels (S1 to S6) had various spans $(2750 \mathrm{~mm}$ to $3750 \mathrm{~mm})$. The five shear connectors were integrated into the design formulation of the concrete wythes. Panels S1 and S2 deflected at the same time, especially at the elastic stage. This deflection continued until just before the load of failure was applied. Panels S3, S4, and S5 gradually deflected because of the influence of their aspect ratios. However, the panels with lower aspect ratios exhibited a high composite behavior, particularly for panels with aspect ratios $(\mathrm{L} / \mathrm{d}) \geq 21.67$, under which they exhibited a stiffer behavior in comparison with other panels with higher aspect ratios . But, all panels (S1 to S6) exhibited high composite behavior, especially the panels with an aspect ratio (L/d) $\leq$ 19.12, which projected a slightly stiffer behavior compared with the panels with an aspect ratio $(\mathrm{L} / \mathrm{b})>$ 16.18 (Fig. 8). The rigidity and stiffness provided by the shear connectors mainly influenced the high reliability of the 2D FEA model analysis. However, it found that the ultimate load for panel S1 was greater than that for S6 by about $79.2 \%$ in the FEA models and $52.3 \%$ in the experimental test when the aspect ratio of the panels increased from 16.18 to 23.53.

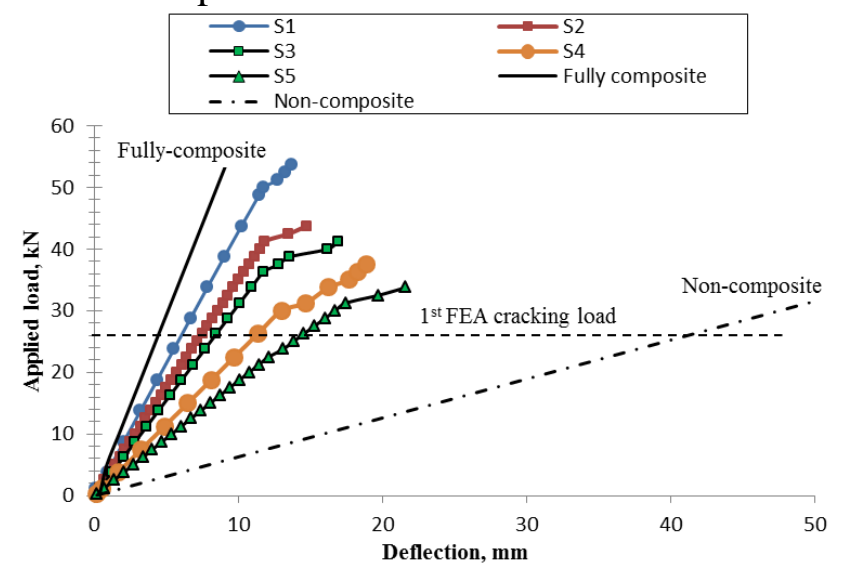

Fig. 8: Typical deflection profile at FD2 of mid-span for panels S1 to S6 
Fig. 9 illustrates the deflection profiles along the span of slab panels S1 and S6 at different load stages. The deflection at the mid-span of the slabs was high; at this point, the loads were highly concentrated at the midpoint of the panel span. The panels with higher aspect ratios were more likely to deflect compared with the panels with lower aspect ratios. For example, the deflection values of all panels obtained in the experimental tests were relatively significant compared with those obtained in the FEA models. Also, the deflection of panel S6 of $\mathrm{L} / \mathrm{d}=23.53$ was higher that of $\mathrm{S} 1$ of $\mathrm{L} / \mathrm{d}=16.18$ by approximately $72.5 \%$. The deflection values in all panels obtained via the experimental tests and FEA were comparatively significant.

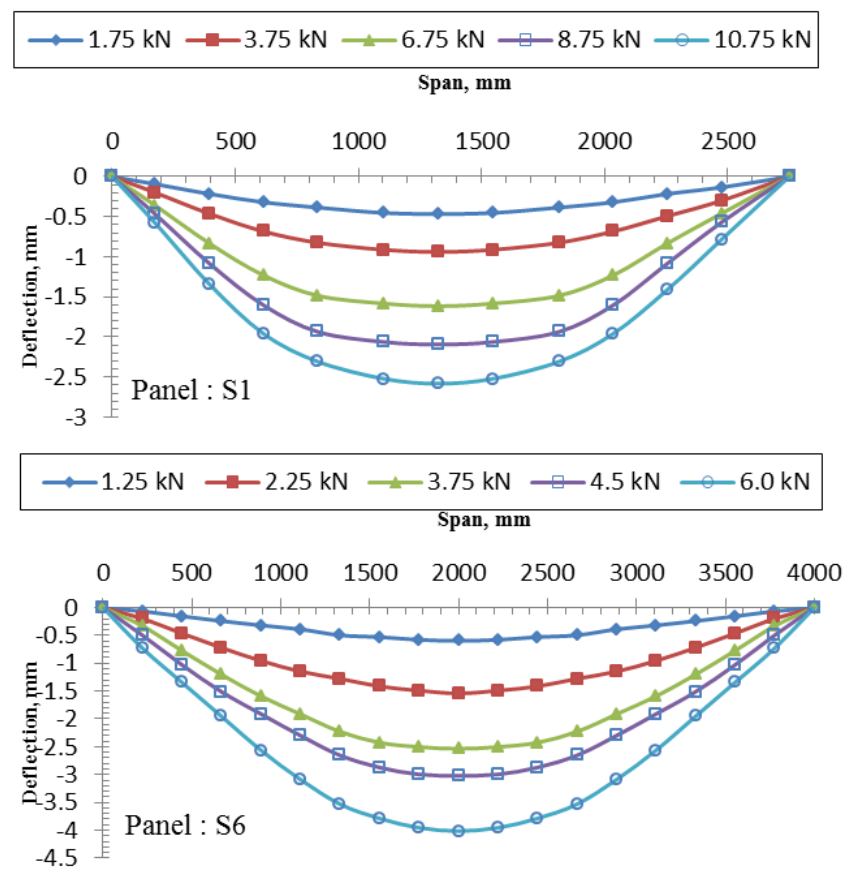

Fig. 9: Deflection profiles of panels S1 and S6 at different load stages (for one shear connector, FEA)

\section{B. Strain Distribution}

Fig. 10 display the strain distribution across the depth of the panels at mid-span for four LFCCSPs S1 of $\mathrm{L} / \mathrm{d}=16.18$ and $\mathrm{S} 6$ of $\mathrm{L} / \mathrm{d}=23.53$ at different load stages. A very small strain discontinuity at the initial load stages was observed across the full depth of the wythes for panels S1 and S6. However, the discontinuity became significant just before the application of the failure loads, which were proportional to the approaching loads. The panels tended to exhibit fully composite behavior because both concrete wythes had merely one neutral axis. The shear connectors used offered effective stiffness, which helped in achieving a high degree of composite action for the panels. In conclusion, all panels achieved a fully composite action.

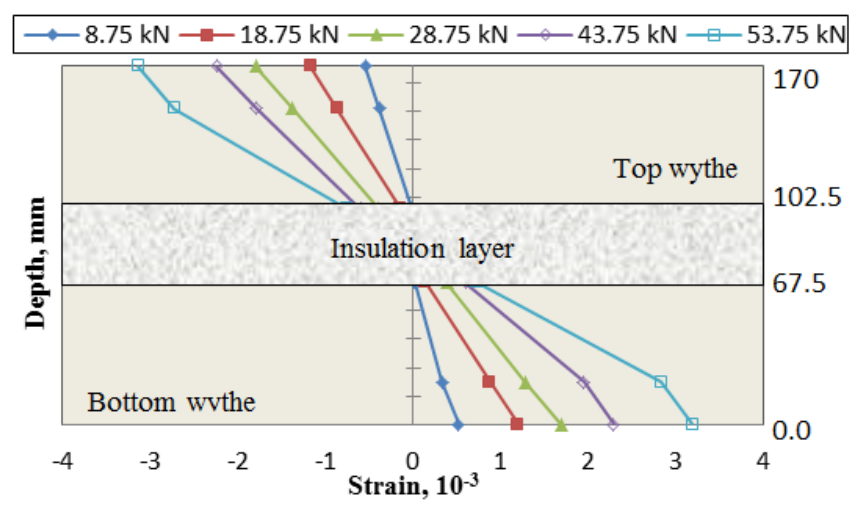




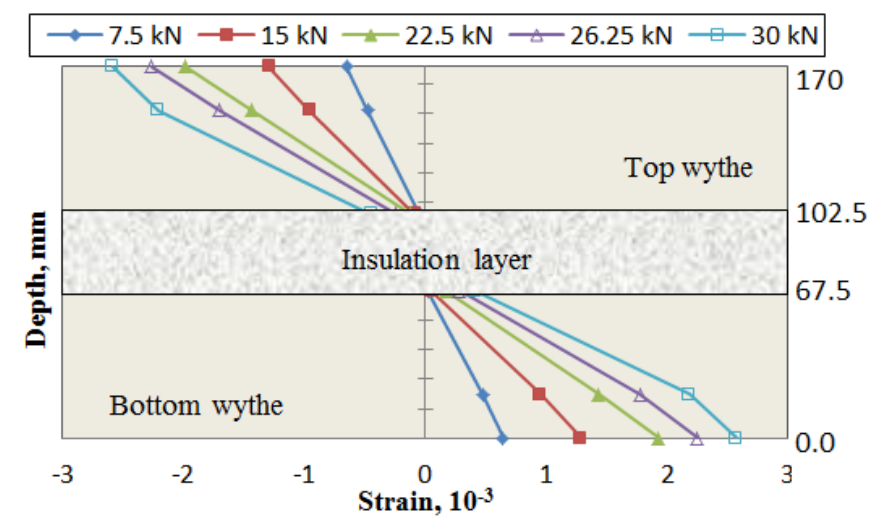

Fig.10: Strain distribution across the $170 \mathrm{~mm}$ depth at different load stages for panel S1 and S6

\section{Strain in the Steel Reinforcement}

Fig. 11 presents the out-of-plane load versus the strain in the steel reinforcement of the bottom concrete wythe at mid-span. Similar to that in practice, the strain at failure exceeded the yield strain of steel (0.02), and this effect indicated that the failure of the panels might have been caused by the yielding of the steel bars before the failure of concrete. The ultimate failure load was caused by the yielding of steel reinforcement accompanied by massive cracking patterns at the bottom concrete wythe of the LFCCSP slab. For the sake of illustration, the typical cracking patterns of the bottom wythe revealed through the FEA models are depicted in Fig. 11.

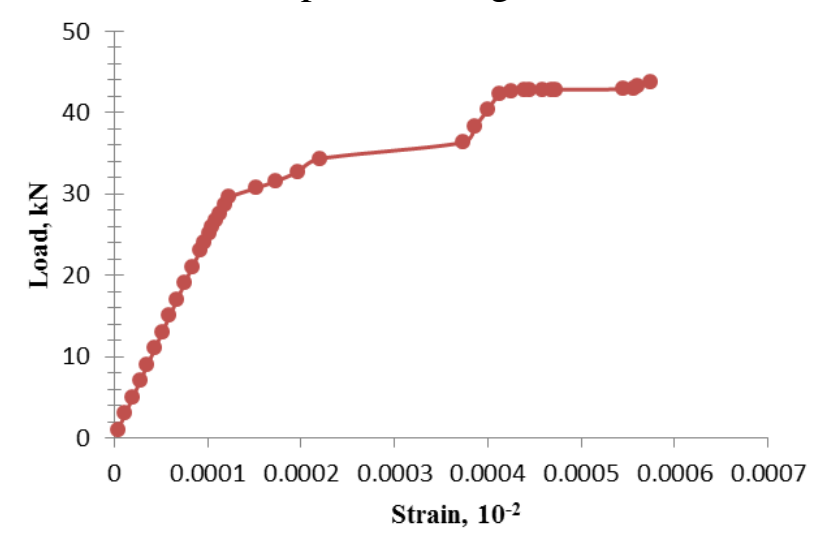

Fig.11: Typical load vs. strain in steel of the bottom wythe at mid-span (FEA)

\section{COMPARISON OF RESUltS}

\section{A. The 2D FEA Model of One-Way LFCCSP Slab}

The 2D FEA model of a one-way LFCCSP slab was built as a 2D continuum by adopting a $240 \mathrm{~mm}$ horizontal cross section across the full panel span. FC and steel (main reinforcement bars and shear connectors) were modeled by assigning four-node $2 \mathrm{D}$ isoparametric plane stress elements and 2D isoparametric bar elements, respectively. The areas of steel reinforcement bars were inserted, and the adopted depth was similar to that of the actual specimens. Shear connector areas were added to make the axial stiffness simulation possible. Fig. 12 shows the ultimate load versus the mid-span deflection curve for panel S6, for both study approaches. The FEA models and experiments at different load stages are also shown. The same figures show the curves corresponding to the theoretical extremes of the fully composite and non-composite actions using classical elastic theory. Experimentally, panel S6 exhibited great composite behavior in the early stages until the appearance of the first crack load. However, the panels tended to behave like semi-composites until the application of the failure load. Analytically, the FEA models became considerably stiffer than the actual tested specimens after the cracking occurred, specifically at the final failure load. However, both study approaches exhibited a perfect bond between concrete and steel. The deflection curves differed possibly because the FEA models behaved in a stiffer manner or because of the unintended errors that could have occurred in the laboratory experimental testing. A comparison with the FEA models showed that the experimental ultimate load for panel S6 
increased by about $6.57 \%$. Therefore, the experimental load was in good agreement with the FEA model load, and a significant correlation was established. The deflections at the first crack for panel S6 in the experiment were higher than those obtained with the FEA models by about $2.71 \%$. Consequently, the experimental investigations and FEA model prediction presented an acceptable accuracy of deflections, especially at the elastic stage, but in general, the FEA models were less captured the actual behaviors of test specimens and ultimate failure load for one-way acting LFCCSP slabs under out-of-plane loadings. In conclusion, the values obtained from the experiments and FEA models were acceptable and showed sufficient bounds integrated by five truss-shaped shear connectors (stiffness).

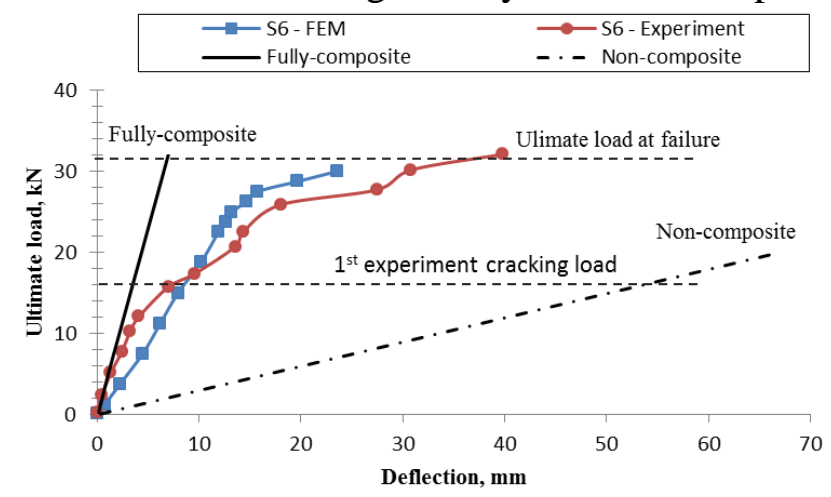

Fig. 12: Load-deflection profile at FD2 of mid-span for panel S6 of $170 \mathrm{~mm}$

\section{B. Strain in the Shear Connector Legs at Mid-Span}

Fig. 13 illustrates the typical strain versus the applied load of the shear connectors located in the panel mid-span of the tested specimen S4. The same figure also depicts the predicted strains of the FEA approach based on the 2D model. Conservative strain values were provided in the shear connector. Moreover, the strain based on the FEA model was stiffer than the strain recorded via the experiment. The difference between the FEA model and the experimental strain values was almost $8.4 \%$ at the ultimate load at failure. Consequently, the 2D FEA model established an applicable method that can be used to compute the axial forces within shear connectors, which are important parameters required for designing purposes in practical use.

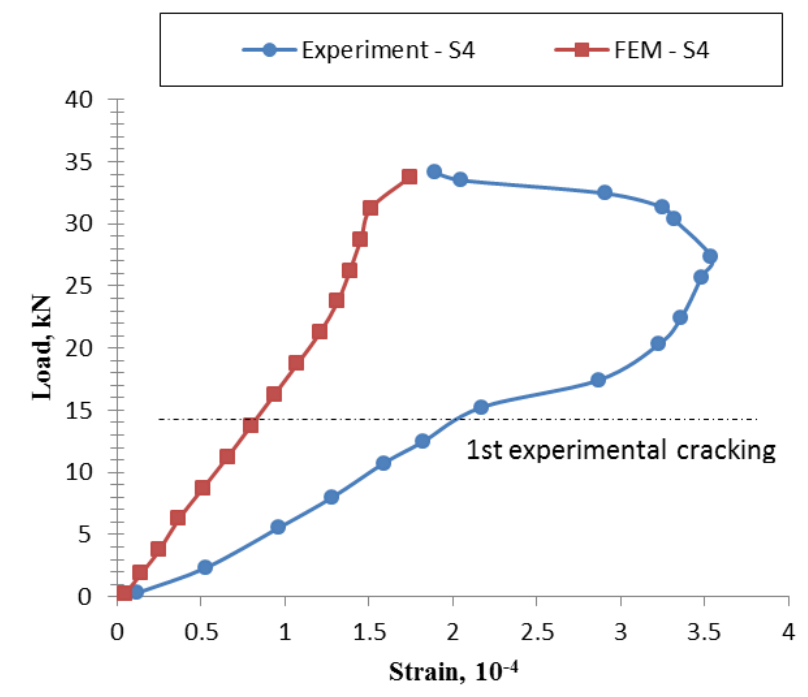

Fig. 13: Load vs. strain on the shear connector leg at mid-span

\section{SUMMARY AND CONCLUSION}

The structural behaviour of total full-scale six LFCCSP specimens with variable aspect ratios ranging from 16.18 to 23.53, respectively, tested under out-of-plane load. The experiment results were discussed with respect to the load-deflection profiles, load-strain relationships, and strain distribution across the entire panel depth, and aspect ratio influence. The deflection behavior along the span of the LFCCSP slabs 
at different load stages was determined. The influence of the span-to-depth ratio $(\mathrm{L} / \mathrm{d})$ on the ultimate capacity of LFCCSP slabs to carry out-of-plane loads was reported and the composite action was also studied. Typical failure occurred because of the major cracks that significantly widened along the span at the bottom concrete wythe, especially at the mid-span. The first flexural cracks were recorded at loads of $41 \%$ to $52 \%$. The crack patterns initially emanated from the bottom wythe and extended to the top concrete wythe without the top concrete wythe de-bonding. However, a minor de-bonding was observed in panel S6, which might have been caused by the effect of the aspect ratio (L/d). However, it found that the ultimate flexural strength capacity of the tested slab specimens non-linearly decreased by approximately $52.3 \%$ for an L/d increase from 16.18 to 23.53 . The adopted FEA model results were analysed, including the degree of composite action at the elastic and ultimate stages. The ultimate flexural strength decreased by around $79.2 \%$ for an L/d increase from 16.18 to 23.53 . The test results and FEA model data were compared with the theoretical values computed by assuming LFCCSP as a fully composite and a significant degree of accuracy was obtained. Based on the results obtained, therefore, the LFCCSP slab can serve as an alternative to the normal concrete slab system in buildings.

\section{ACKNOWLEDGEMENT}

The authors gratefully acknowledge the financial support by corporation of the Department of Civil Engineering, Faculty of Engineering, Amran University, Yemen, and Department of Civil Engineering, College of Engineering, Prince Sattam Bin Abdulaziz University, KSA for this research.

\section{REFERENCES}

[1] Kang, J. (2015). Composite and non-composite behaviors of foam-insulated concrete sandwich panels. Composites Part B: Engineering, 68: 153-161.

[2] Chen, A., Norris, T. G., Hopkins, P. M., and Yossef, M. (2015). Experimental investigation and finite element analysis of flexural behavior of insulated concrete sandwich panels with FRP plate shear connectors. Engineering Structures, 98: 95-108.

[3] Benayoune, A., Samad, A. A., Trikha, D. N., Ali, A. A., and Ellinna, S. H. M. (2008). Flexural behaviour of pre-cast concrete sandwich composite panel-Experimental and theoretical investigations. Construction and Building Materials, 22(4): 580-592.

[4] Noridah, Mohamad (2010). The structural behaviour of precast lightweight foamed concrete sandwich panel as a load bearing wall. PhD Thesis, Universiti Teknologi Malaysia (UTM), Malaysia.

[5] Yavuz Yardim (2008). Development of lightweight composite slabs system for residential building. $\mathrm{PhD}$ thesis. Department of civil engineering, Universiti Putra Malaysia (UPM), Malaysia.

[6] Salmon, D. C., Einea, A., Tadros, M. K., and Culp, T. D. (1997), Full scale testing of precast concrete sandwich panels. ACI Structural Journal, 94: 239-247.

[7] Mydin, M. A. O., and Wang, Y. C. (2011). Structural performance of lightweight steel-foamed concrete-steel composite walling system under compression. Thin-walled structures, 49(1), 66-76.

[8] Kabir, M. Z. (2005). Structural performance of 3-D sandwich panels under shear and flexural loading. Journal of Scientifica Iranica, 12(4): 402-408.

[9] Samsudin, S., and Noridah, M. (2013). Structural Behaviour of Precast Lightweight Foamed Concrete Sandwich Panel under Axial Load: An Overview. International Journal of Integrated Engineering, 4(4).

[10] Mouli, M., and Khelafi, H. Strength of short composite rectangular hollow section columns filled with lightweight aggregate concrete. Engineering structures, 29(8), (2007) 1791-1797.

[11] Ramamurthy, K., Nambiar, E. K., and Ranjani, G. I. S. A classification of studies on properties of foam concrete. Cement and concrete composites, 31(6) (2009) 388-396.

[12] Valore Jr, R. C. Cellular concretes part 2 physical properties. ACI Journal Proceedings, 50(6) (1954). 
[13] Y.H. Mugahed Amran, Nima Farzadnia, and AA Abang Ali. Properties and applications of foamed concrete; a review. Construction and Building Materials, 101 (2015) 990-1005.

[14] Y.H. Mugahed Amran, Raizal S.M. Rashid, Farzad Hejazi, Nor Azizi Safiee, A. A.A bang Ali. Response of precast foamed concrete sandwich panels to flexural loading. Journal of Building Engineering, 7 (2016) 143-158.

[15] Benayoune, A. (2003). Precast reinforced sandwich panels as a building system. PhD thesis, University Putra Malaysia (UPM), Malaysia.

[16] Ellinna, S.H.M. (2002). The behaviour of precast concrete sandwich panel as slab. B.E. Report, Universiti Putra Malaysia (UPM), Malaysia. 